\title{
Cyberbullying: Percepções acerca do Fenômeno e das Estratégias de Enfrentamento
}

\section{Cyberbullying: Perceptions about the Phenomenon and Coping Strategies}

\author{
Sidclay Bezerra Souza* ${ }^{*}$, Ana Margarida Veiga Simão ${ }^{a} \&$ Ana Paula Caetano ${ }^{b}$ \\ ${ }^{a}$ Faculdade de Psicologia da Universidade de Lisboa, Lisboa, Distrito de Lisboa, Portugal \\ ${ }^{b}$ Instituto de Educação da Universidade de Lisboa, Lisboa, Distrito de Lisboa, Portugal
}

\begin{abstract}
Resumo
O cyberbullying, caracterizado como um dos tipos de violência em contexto educativo, apresenta-se como uma das principais causas do mal-estar vivido por seus protagonistas. O estudo inserido no Projeto Cyberbullying - o diagnóstico da situação em Portugal pretendeu compreender o fenômeno a partir das vivências de 118 estudantes do primeiro ano do Ensino Superior público português, que responderam a um questionário. Pudemos perceber a percepção dos alunos sobre o fenômeno e a importância que pares, professores e pais apresentam no enfrentamento e prevenção do cyberbullying. Tais resultados orientam-se no sentido do desenvolvimento sistêmico de comunidades que se fortalecem internamente para que cada um se sinta autorizado a intervir e a cuidar dos que nelas são vítimas de violência.

Palavras-chave: Cyberbullying, estratégias de enfrentamento, perspectivas dos alunos.

Abstract

Cyberbullying is characterized as one of the different types of violence in educational contexts and is one of the main causes of uneasiness felt by its protagonists. It is also considered as one of the challenges of contemporary education. The study inserted in the project Cyberbullying - a diagnosis of the situation in Portugal intended to understand the phenomenon, its extension and nature through the experience of 118 first year psychology students in the Portuguese public higher education system. Participants responded to a questionnaire of open and closed-ended questions. From the analyses done we understand the students' perceptions regarding the phenomenon, as well as the fundamental importance peers, teachers and parents/legal guardians have in coping with and preventing cyberbullying. These results demonstrate that there is the need to systemically develop communities that may internally strengthen themselves so that each individual feels authorized to intervene and care for those that are the victims of violence.

Keywords: Coping strategies, cyberbullying, student perceptions.
\end{abstract}

A violência no contexto educativo é uma das principais causas do mal-estar vivido por diversos de seus atores, apresentando-se como um dos problemas atuais da educação contemporânea. Conforme nos conferem Francisco e Libório (2009), "a escola, multifacetada, vem presenciando situações de violência que estão tomando proporções assustadoras em nossa sociedade. As situações de violência, anteriormente esporádicas, se tornaram uma constante em nossos dias" (p. 200). Esse mal-estar é vivenciado nas relações entre alunos, professores e demais profissionais da educação, dificultando, assim, o processo de ensino-aprendizagem, bem como o desenvolvimento social e

\footnotetext{
* Endereço para correspondência: Universidade de Lisboa, Alameda Universidade, Alvalade, Lisboa, Portugal 1649-004. E-mail: ssouza@campus.ul.pt, amsimao@ psicologia.ulisboa.pt e apcaetano@ie.ulisboa.pt. Este artigo foi desenvolvido como parte das atividades do Doutoramento do primeiro autor em Psicologia, especialidade Psicologia da Educação. Sendo o mesmo, bolsista do Centro de Aperfeiçoamento de Pessoal de Nível Superior (CAPES) pelo Programa de Doutorado Pleno no Exterior (Proc. n. ${ }^{\circ}$ BEX 1710/13-3).
}

afetivo das pessoas envolvidas. A Organização Mundial de Saúde (2002), por sua vez, aponta a questão da violência como um problema de saúde pública, a nível mundial, indicando a violência juvenil com um dos aspectos mais alarmantes nos últimos anos.

O bullying, palavra de origem inglesa, é caracterizado como um comportamento consciente, intencional, deliberado, hostil e sistemático, de uma ou mais pessoas, cuja intenção é ferir os outros. Tal fenômeno começou a ser investigado a partir dos estudos realizados por Dan Olweus, na Universidade de Bergen - Noruega, iniciados no fim da década de 1970. Olweus foi o pioneiro nas investigações sistemáticas sobre a problemática, tendo publicado os seus resultados na obra Aggression in the Schools: Bullies and Whipping Boys (1978).

Como uma nova forma de expressão do bullying, o cyberbullying é caracterizado por Slonje e Smith (2008) como uma manifestação de agressão ou assédio moral, que ocorre por meio de recursos tecnológicos modernos, especificamente, telefones celulares ou pela internet. De acordo com Silva e Mascarenhas (2010, p. 51) 
Souza, S. B., Veiga Simão, A. M. \& Caetano, A. P. (2014). Cyberbullying: Percepções acerca do Fenômeno e das Estratégias de Enfrentamento.

em contraste com outras formas de bullying, o cyberbullying, apoiado nas tecnologias da informação, transcende as fronteiras do tempo (na medida em que a ofensa se pode manter infinitamente presente no espaço virtual), mas também as fronteiras do espaço pessoal e físico.

As investigações sobre esse tema ainda se encontram numa fase inicial, embora as evidências científicas apontem que o fenômeno tenha adquirido uma maior dimensão com o aumento do uso de dispositivos eletrônicos tais como computadores e telefones móveis. Tal fato é mencionado por Amado, Matos e Pessoa (2009a) sugerindo que as investigações sobre o cyberbullying, embora muito incipientes, traduzem-se, por um lado, numa grande e comum perplexidade perante os casos e, por outro, na sensação de que, para intervir com eficácia educativa, ainda há muito que se aprender e experimentar.

Freire, Veiga Simão e Ferreira (2006) apresentam o bullying, assim como o cyberbullying, como manifestações da violência no contexto educativo, havendo o tema atingido grande visibilidade na literatura, nomeadamente pelo seu estudo em diversos países. Suas repercussões têm colocado em xeque o conceito e função do contexto educativo, enquanto espaço propiciador de aprendizagem, como também de construção de vínculos e afetos, ambos marcados por um processo de relação entre pessoas, contextualizado no tempo e no espaço. Trata-se de aprofundar uma visão sistêmica e multifacetada dos fatores e das formas de intervenção face ao problema, onde todos se sintam investidos de uma responsabilidade ética para intervir e apoiar os que precisam.

Em Portugal, no que diz respeito especificamente à população jovem, população que apresenta maior percentagem na problemática abordada, em investigações realizadas por Cardoso, Espanha e Lapa (2007), e Grupo Marktest (2008), verifica-se que $70 \%$ das crianças e jovens estudados usam a internet e que, destes 70\%, 85,6\% a usam regularmente. Nos alunos com idade entre 8-12 anos, a percentagem de utilizadores é de $57 \%$, aumentando para os mais velhos, pois entre os 13-15 anos a percentagem é de $84,3 \%$, e entre $16-18$ anos é de $76,9 \%$.

Conforme salientam Amado, Matos e Pessoa (2009b) existe um número limitado de estudos que abordam este problema específico, tornando mais difícil formar um quadro realista da situação em Portugal. O conhecimento acerca do assunto ainda é baseado em relatórios individuais e ocasionais, como também em estudos feitos para diagnosticar a incidência do cyberbullying nas escolas. Assim, o tema do cyberbullying em Portugal, como em outros países, juntamente com a questão de como fazer melhor uso das novas tecnologias, tornou-se uma preocupação importante para a sociedade (Amado et al., 2009b).

Percepções dos Alunos sobre o Cyberbullying e as Estratégias de Enfrentamento face à Problemática

Com o crescimento de investigações que estudam a violência no contexto educativo, têm-se evidenciado a universalidade do fenômeno, embora a sua manifestação adquira variações particulares em cada cultura (Castilho, 2010). Com a intenção de melhor compreender o cyberbullying na sua complexidade, marcado pela potencialidade das tecnologias, nada melhor do que compreendê-lo a partir da percepção dos alunos. Abordar a problemática deste ponto de vista, possibilita uma aproximação maior ao fenômeno do cyberbullying, favorecendo elementos para equacionar uma intervenção preventiva e atuante sobre suas consequências. Um aspecto relevante e característico encontra-se no anonimato dos agressores que a internet $\mathrm{e}$ outras Tecnologias da Informação e Comunicação (TIC) podem proporcionar. Como se já não bastassem os infortúnios da difamação a seu respeito, a vítima também encontrará em seu caminho alguns desafios peculiares das novas tecnologias, pois o mundo virtual permite ao agressor sentir-se menos inibido e, ao mesmo tempo, não ser responsabilizado por suas ações (Souza, 2011).

Tendo em vista as consequências na vida das vítimas e demais envolvidos, as estratégias utilizadas por estes face ao fenômeno são de extrema importância, uma vez que buscam diminuir o seu sofrimento, como também uma ação interventiva e preventiva das possíveis consequências. Castilho (2010) considera as estratégias de enfrentamento como o manejo de esforços cognitivos e comportamentais para lidar com demandas específicas. Neste sentido, as estratégias surgem ou para atuar sobre as situações vividas e/ou sobre o significado valorativo atribuído ao fenômeno (numa lógica cíclica, em que poderá alterar as emoções $\mathrm{e}$, consequentemente, as estratégias utilizadas num novo episódio, caso aconteça).

O enfrentamento começa a partir da avaliação inicial, realizada por um dos diversos atores do contexto educativo da situação de bullying, acerca da sua intensidade, duração, frequência, bem como das características dos envolvidos. Ao mesmo tempo em que a avaliação inicial possibilita perceber a situação, permite, em seguida, identificar recursos e selecionar uma ou um conjunto de estratégias de enfrentamento adequadas para cada caso específico (Souza, 2011). Desta forma, as estratégias de enfrentamento consistiriam nos processos específicos utilizados em cada contexto e podem ser alteradas em função das situações desencadeadoras (Castaño \& Barco, 2010).

Price e Dalgleish (2010) afirmam que as estratégias utilizadas para resolver o cyberbullying têm recebido uma atenção considerável na literatura, sendo estas, formas de enfrentamento ou atitudes face ao fenômeno, podendo ser tomadas tanto individualmente como por amigos dos envolvidos, quer pela comunidade educativa, como também pelos pais ou encarregados de educação.

Ao mesmo tempo, as tecnologias de informação e comunicação criaram novos desafios para os educadores, que afirmam estar despreparados e um tanto incertos sobre como lidar com a ocorrência de casos concretos (Shariff, 2011). Exemplificando um desafio específico sobre a estratégia de "pedir ajuda", Campbell (2005), constatou que muitos dos jovens não denunciam o caso 
por acharem que os adultos não acreditarão ou banalizarão a sua denúncia.

Em busca desta caracterização geral, formulou-se um conjunto de interrogações específicas (e.g., qual a natureza e a dimensão do fenômeno, qual o perfil dos envolvidos em situações de cyberbullying; qual a concepção dos alunos sobre o cyberbullying, que tipos de estratégias são apontadas para enfrentar o cyberbullying), relacionadas com a utilização das TIC, que não só permitisse compreender o fenômeno do cyberbullying, como também possibilitasse a construção de um instrumento válido de pesquisa, contribuindo para fornecer uma ideia realista do problema.

Tendo como base os aspectos apontados sobre a problemática apresentada, objetivou-se compreender a percepção dos participantes acerca do cyberbullying, bem como identificar as suas possíveis estratégias de enfrentamento. Assim, o estudo pretende contribuir para uma melhor compreensão do fenômeno cyberbullying, a fim de proporcionar resultados que permitam equacionar futuros projetos de prevenção, intervenção e investigação.

\section{Método}

Trata-se de um estudo exploratório e descritivo do fenômeno cyberbullying numa amostra por conveniência de estudantes do ensino superior, mais precisamente, alunos do primeiro ano de um curso de Psicologia. O projeto em que este estudo se insere foi aprovado pela Fundação para a Ciência e Tecnologia (FCT) e está registado com o título: Cyberbullying: Um diagnóstico da Situação em Portugal, e com a referência: PTDC/CPE-CED/108563/2008, sendo financiado no âmbito do Programa Operacional Temático Fatores de Competitividade (COMPETE) e comparticipado pelo Fundo Europeu de Desenvolvimento Regional (FEDER).

\section{Amostra}

A amostra deste estudo foi composta por um total de 118 participantes ( 100 do gênero feminino e 18 do gênero masculino), representando $86 \%$ dos estudantes do primeiro ano do ensino superior público de Lisboa (Portugal), de um curso de Psicologia, com as idades variadas entre 19 a 50 anos.

\section{Instrumento}

O questionário exploratório construído pela equipe do projeto é composto por um total de 53 itens, com perguntas de respostas abertas e fechadas, com o objetivo de tentar perceber e, sobretudo, explorar aspectos relacionados com dados sociodemográficos dos participantes, a caracterização das vítimas, dos agressores, das testemunhas, como também perceber qual a percepção dos alunos do ensino superior sobre o cyberbullying. Mais precisamente, os quatro primeiros itens buscam perceber alguns dados demográficos, como idade, curso, ano do curso que frequenta e sexo. Já os itens de 5 a 5.11 , têm o objetivo de identificar aspectos relacionados com as vítimas, incluindo o conhecimento das vítimas a respeito do agressores, o tipo de tecnologia utilizada, o ano de escolaridade em que o fato ocorreu, bem como uma descrição, por parte da vítima, sobre o fato. Ainda é possivel verificar nestes itens o sentimento das vítimas face à agressão, suas reações, os motivos dos agressores na concepção das vitimas, e por fim, tenta perceber se as vítimas acham ter tido alguma culpa pelo que aconteceu e por quais motivos. Os itens de 6 a 6.11 , buscam identificar os agressores e seus alvos, bem como o tipo de tecnologia utilizada, os motivos que o levaram à agressão, o ano de escolaridade do episódio, o local onde aconteceu a agressão, o sentimento das vítimas na concepção do agressor, bem como suas consequências possíveis. Os itens de 7 a 7.10 e de 8 as 8.8 visam identificar testemunhas, bem como compreender o episódio a partir de uma descrição do participante. Já os itens de 9 a 14 buscam avaliar qual a percepção dos participantes acerca desses atos, o que podem fazer as vítimas, a quem e como as vítimas podem pedir ajuda, o que devem fazer os colegas para ajudar nestas situações e como os professores e os pais podem ajudar a evitar esses problemas.

Com base nos resultados deste estudo exploratório e de entrevistas realizadas a estudantes foi feito o fechamento do questionário que se encontra atualmente em fase de análise das qualidades psicométricas.

\section{Processo de Recolha e Tratamento de Dados}

Após o consentimento informado dos professores e dos estudantes do $1^{\circ}$ ano do curso de Psicologia, foi aplicado o questionário nas diversas turmas (que teve a duração média de 35 minutos). Na fase da recolha, tendo em vista as recordações de desconforto que poderiam emergir durante o preenchimento do questionário, foi disponibilizado aos participantes a presença de um psicólogo clínico como apoio. Neste caso, $5 \%$ dos participantes sentiram necessidade de recorrer ao apoio oferecido e mencionaram a importância de estudos sobre a problemática, como também puderam narrar aspectos específicos da sua experiência pessoal num caso de cyberbullying. Para além de uma estatística descritiva sumária às perguntas de resposta fechada, procedemos a uma análise de conteúdo das respostas às perguntas abertas.

Para análise dos dados, adotamos uma abordagem indutiva, recorrendo à categorização que consistiu na inferência das categorias, indicadores, unidades de registo e na contagem da frequência das respostas obtidas. Para tal, buscou-se seguir os critérios de categorização semântica, apontados por Amado (2000) e Bardin (2009) que consistem na exclusão mútua, homogeneidade, pertinência, objetividade e fidelidade e produtividade. Em seguida, as categorias, indicadores e unidades de registro foram submetidos a juízes, acautelando assim questões de validade e de fidelidade, possibilitando reflexões e aprimoramento da técnica, bem como uma inferência mais precisa.

Vale ressaltar que no tratamento dos dados referente ao tipo de envolvimento dos participantes, tendo em vista a possibilidade dos mesmos terem vivenciado o fenômeno como vítima e testemunha, verificou-se que isso repercutiu nos resultados obtidos, uma vez que os alunos apontam para mais de um tipo de envolvimento no cyberbullying. 
Souza, S. B., Veiga Simão, A. M. \& Caetano, A. P. (2014). Cyberbullying: Percepções acerca do Fenômeno e das Estratégias de Enfrentamento.

Ao longo do questionário os participantes podiam referir mais de uma estratégia o que justifica o fato de se obterem somatórios de percentagens de participantes superiores a $100 \%$. Assim o $f$ corresponde ao número de participantes que referiu cada uma das estratégias e a \% é calculada tendo por referência o total dos participantes, ou seja, 118 alunos.

\section{Apresentação e Discussão dos Resultados}

Numa primeira análise sobre a ocorrência de episódios de cyberbullying vivenciados pelos alunos, foi possível caracterizar o tipo de envolvimento dos participantes em situações de cyberbullying, verificando-se que $18,6 \%$ dos participantes estiveram envolvidos como vítimas, $59,3 \%$ como testemunhas, $39,8 \%$ dos participantes mencionaram nunca terem se envolvido em casos de cyberbullying, não sendo possível identificar algum tipo de envolvimento dos participantes como agressor.

Em análise mais aprofundada sobre os tipos de envolvimento dos participantes, especificamente sobre as vítimas, $81,8 \%$ dos participantes são do gênero feminino e $18,1 \%$ do gênero masculino. Questionadas as vítimas sobre os autores dos fatos, salientam que $39,3 \%$ eram do gênero feminino e $60,7 \%$ do gênero masculino. Quanto à questão do tipo de tecnologia utilizada no caso das vítimas de cyberbullying, foi possível perceber que o computador $(51,7 \%)$ apresentou-se como instrumento mais utilizado que o telefone celular (9,3\%), e em alguns casos, os alunos utilizam ambas as ferramentas.

No sentido de ampliar a compreensão a respeito das testemunhas, bem como perceber a dinâmica de seu envolvimento, foi-nos possível identificar três tipos: testemunhas das vitimas - $(61,4 \%)$ : àqueles que testemunharam algum episódio de cyberbullying a partir do conhecimento obtido por meio do sofrimento da vítima; testemunhas dos agressores - $(10,0 \%)$ : os que presenciaram o comportamento hostil dos agressores; e as testemunhas do tipo misto - $(27,1 \%)$ : àqueles que testemunharam tanto o sofrimento e desconforto das vítimas, como também o comportamento de intolerância dos agressores. Ainda referente às testemunhas, de acordo com as informações obtidas quanto aos autores do fato, $64,1 \%$ informaram que se tratava de uma pessoa do gênero feminino; $13,5 \%$ de uma pessoa do gênero masculino; $3,7 \%$ de um grupo do gênero feminino; $9,8 \%$ de um grupo do gênero masculino e $8,6 \%$ apontaram que se tratava de um grupo misto. Enquanto que o telefone móvel é apontado por apenas $25,4 \%$ dos alunos inqueridos, o computador é indicado por $75,4 \%$ dos participantes.

\section{Percepções dos Alunos sobre o Cyberbullying}

Relativamente às percepçõess dos jovens sobre $o c y$ berbullying, foram identificados alguns aspectos relevantes para a compreensão do fenômeno. $\mathrm{O}$ primeiro aspecto indica alguns fatores conceituais do problema, composto por uma percepção do ponto de vista tecnológico e outra comportamental. Sob uma percepção com base nos apa- ratos tecnológicos, os alunos consideram o cyberbullying como "uso inadequado das tecnologias e redes sociais" $(5,0 \%)$, e que "pertence ao mundo virtual" $(2,5 \%)$. Já no que diz respeito à questão comportamental, o cyberbullying é considerado como um "ato cruel e desumano" $(16,1 \%)$; como um "ato irresponsável e sem justificativa" (39,9\%); um "ato de covardia" (11,0\%). Ainda foi possível identificar que os alunos consideram o cyberbullying como "um ato de difícil intervenção" $(0,8 \%)$, e ainda como uma "brincadeira" $(1,6 \%)$. Vemos, assim, que a dimensão de julgamento moral do cyberbullying está muito presente, acentuando-se as consequências dos atos sobre as vítimas e a especificidade desta forma de bullying, onde a não presença do agressor face à vítima propicia uma violência pela qual o perpetrador se esconde por detrás do instrumento virtual utilizado.

O segundo aspecto aponta para algumas causas do fenômeno, sendo caracterizadas como uma visão contextual do cyberbullying em que a "educação" (7,6\%), a "sociedade" $(4,2 \%)$, a "necessidade de diálogo" (3,3\%), a "ausência de atividades produtivas" $(2,5 \%)$, bem como a "família" $(1,6 \%)$, foram indicados como parte integrante dos seus fatores. No conjunto destas respostas, e apesar destas não serem dadas pelos mesmos participantes, pudemos inferir a dimensão sistêmica do problema, que extravasa a dimensão intrapsíquica e relacional dos intervenientes diretamente envolvidos. Outro fator indicado pelos alunos aponta para aspectos relacionados ao agressor, em que a "personalidade" (11,0\%), a "necessidade de autoafirmação" $(8,4 \%)$, "necessidade de controle e intervenção" (6,7\%); "necessidade de aceitação" 5,0(\%); e a "necessidade de vingança do agressor" $(2,5 \%)$, foram indicados como responsáveis pelo desencadeamento do fenômeno. Ainda foi identificada uma perspectiva "multifatorial" $(1,6 \%)$, em que além dos aspectos acima mencionados, existem outros fatores que podem estar presentes na causa do cyberbullying, o que necessita de maior investigação.

$\mathrm{O}$ terceiro aspecto a ser considerado, indicado pelos alunos, diz respeito às consequências do cyberbullying, sejam relacionados às vítimas, como também ao agressor. Não foi possível identificar nas respostas dadas pelos alunos nenhuma menção às consequências na vida das testemunhas. Relativamente às consequências direcionadas às vítimas, os alunos indicam o "sofrimento vivenciado pela vítima" (18,6\%), e em seguida, o "suicídio" (3,3\%). Os alunos também indicam a "necessidade de maiores informações" acerca do fenômeno (4,2\%), como também acerca dos envolvidos $(1,6 \%)$, seja através de investigações sistemáticas que possibilitem uma maior compreensão do fenômeno, como também nas escolas, nas famílias, nos meios de comunicação, etc.

\section{Tipos de Estratégias das Vitimas de Cyberbullying e seus Direcionamentos, na Perspectiva dos Alunos}

É fundamental conhecer as estratégias utilizadas pelas vítimas, para a construção de programas de intervenção que sejam eficazes em seu contexto e singularidade. $\mathrm{Na}$ 
Tabela 1 podemos observar as estratégias reveladas pelos alunos como offline, online e estratégias mistas. A partir dos estudos realizados por Price e Dalgleish (2010), compreendemos como estratégias offline àquelas utilizadas nos momentos em que as vítimas e/ou as testemunhas não estão conectados ao "mundo virtual" através dos recursos tecnológicos modernos, destacando-se assim, a internet. Por estratégias online compreendemos àquelas em que são utilizadas nos momentos em que as pessoas encontram-se conectadas ao "mundo virtual". Já as estratégias mistas

Tabela 1

Tipos de Estratégias a serem Utilizadas pelas Vítimas de Cyberbullying na Percepção dos Alunos

\begin{tabular}{|c|c|c|c|c|}
\hline Categorias & Subcategorias & Indicadores & $f$ & $(\%)$ \\
\hline \multirow[t]{12}{*}{ Estratégias Offline } & \multirow[t]{5}{*}{ Estratégias de Confronto } & Fazer frente ao fato & 15 & 12,7 \\
\hline & & Confrontar os agressores & 03 & 2,54 \\
\hline & & Identificar os agressores & 03 & 2,54 \\
\hline & & Alertar os envolvidos & 01 & 0,84 \\
\hline & & Não Calar & 09 & 7,62 \\
\hline & \multirow[t]{5}{*}{ Estratégias de Pedido de Ajuda } & Contatar autoridade policial & 49 & 41,5 \\
\hline & & Buscar apoio profissional & 10 & 8,4 \\
\hline & & Procurar a ajuda de alguém de confiança & 42 & 35,5 \\
\hline & & Pedir ajuda à família & 23 & 19,4 \\
\hline & & Pedir ajuda aos amigos & 06 & 5,04 \\
\hline & \multirow[t]{2}{*}{ Estratégias de Evitamento } & Evitar contato com os agressores & 03 & 2,5 \\
\hline & & Ignorar o fato e/ou o(s) agressores & 17 & 14,4 \\
\hline \multirow[t]{4}{*}{ Estratégias Online } & \multirow[t]{3}{*}{ Estratégias de Rutura } & $\begin{array}{l}\text { Restringir contatos (e-mail, número } \\
\text { de telefone móvel) }\end{array}$ & 04 & 3,3 \\
\hline & & $\begin{array}{l}\text { Mudar contatos (e-mail, número } \\
\text { de telefone móvel, etc.) }\end{array}$ & 03 & 2,5 \\
\hline & & $\begin{array}{l}\text { Encerrar contatos (e-mail, número } \\
\text { de telefone móvel, etc.) }\end{array}$ & 04 & 3,3 \\
\hline & Estratégias Sociais & Excluir agressores da rede social & 01 & 0,8 \\
\hline \multirow{2}{*}{$\begin{array}{l}\text { Estratégias Online } \\
\text { e Offline }\end{array}$} & Estratégias de Pedido de Ajuda & Contatar gestores dos sites & 07 & 5,9 \\
\hline & Estratégias de Confronto & Identificar os agressores & 03 & 2,5 \\
\hline
\end{tabular}

Nota. $\mathrm{O} f$ corresponde ao número de participantes que referiu cada uma das estratégias. A \% é calculada tendo por referência o total dos participantes, ou seja, 118 .

No âmbito dos contatos indicados pelos alunos, a busca do apoio familiar, social, escolar e do apoio profissional, nomeadamente as autoridades policiais e profissionais das tecnologias são extremamente importantes no enfrenta- seriam àquelas utilizadas em ambos os momentos: offline e online.

As estratégias de enfrentamento, conforme nos propõe Castilho (2010), são consideradas como o manejo de esforços cognitivos e comportamentais para lidar com as demandas específicas, e os objetivos dos contatos mencionados pelos alunos distinguem-se pelo tipo de envolvimento, o que, por sua vez, direcionará o tipo de estratégia ou a conjugação das estratégias utilizadas. Seja offline, online ou mista, as estratégias reveladas pelos alunos apontam para a importância dos pedidos de ajuda, aqui incluindo agentes de autoridade, colegas, família e professores. 
Souza, S. B., Veiga Simão, A. M. \& Caetano, A. P. (2014). Cyberbullying: Percepções acerca do Fenômeno e das Estratégias de Enfrentamento.

das vítimas. Já "identificar e punir os agressores" $(4,2 \%)$, "alertar para as consequências" $(2,5 \%)$, como também "bloquear o agressor" $(0,8 \%)$, são as estratégias mencionadas pelos alunos cujo objetivo encontra-se na identificação, punição e prevenção direcionada aos agressores.

No conjunto das estratégias sobressai a dimensão social e psicossocial, com especial destaque para o apoio de terceiros e para o controle externo sobre o agressor. O apelo à autoridade, à família e aos professores parece reforçar a dificuldade de lidar diretamente e pessoalmente com as situações, sendo também possível inferir a atribuição de gravidade às consequências das mesmas. Reforça-se, ainda, a necessidade de envolver todos na resolução dos problemas, numa perspectiva sistêmica, que possa sustentar o desenvolvimento de verdadeiras comunidades justas, onde todos participem e partilhem responsabilidades e se entreajudem.

\section{Estratégias dos Colegas frente ao Cyberbullying} na Percepção dos Alunos

Os colegas apresentam-se como agentes de fundamental importância no combate e prevenção do cyberbullying. As estratégias utilizadas pelos colegas dependerão do tipo de envolvimento a quem se destina a sua ajuda, sejam às vítimas, aos agressores, ou também no sentido mais amplo de tentar diminuir os impactos causados pelo cyberbullying na vida dos envolvidos (Tabela 2 ).

Tabela 2

Estratégias dos Colegas frente o Cyberbullying na Percepção dos Alunos

\begin{tabular}{lllll}
\hline \multicolumn{1}{c}{ Categorias } & \multicolumn{1}{c}{ Subcategorias } & \multicolumn{1}{c}{ Indicadores } & $f$ & (\%) \\
\hline Estratégias face & Estratégias de Rutura & Quebrar o contato com os agressores & 02 & 1,6 \\
ao Agressor & Estratégias de Evitamento & Não incentivar o comportamento & 06 & 5,0 \\
& & Ignorar provocações & 01 & 0,8 \\
Estratégias face & Estratégias de Confronto & Ajudar a esclarecer os fatos & 02 & 1,6 \\
ao Fenómeno & & Contatar autoridades policiais & 13 & 11,0 \\
Estratégias de apoio & \multirow{2}{*}{$\begin{array}{l}\text { Estratégias de Ajuda Direta } \\
\text { àtima }\end{array}$} & Disponibilizar ajuda à vítima & 72 & 61,0 \\
& & Ouvir a vítima & 03 & 2,5 \\
& & Dialogar sobre o assunto & 02 & 1,6 \\
& & Não recriminar & 05 & 4,2 \\
& \multirow{2}{*}{ Estratégias de Ajuda Indireta } & Buscar apoio profissional & 01 & 0,8 \\
& & Apoiar às vítimas nas medidas necessárias & 23 & 19,4 \\
& & Ajudar a acreditar na vítima & 01 & 0,8 \\
& & Falar com familiares e/ou amigos & 04 & 3,3 \\
& & sobre o fato & 07 & 5,9 \\
\hline
\end{tabular}

Nota. $\mathrm{O} f$ corresponde ao número de participantes que referiu cada uma das estratégias. A \% é calculada tendo por referência o total dos participantes, ou seja, 118 .

Nas estratégias face ao agressor, os alunos indicaram dois tipos de estratégias, especificamente estratégias de ruptura e estratégias de evitamento. Nas estratégias face ao fenômeno, a estratégia de confronto foi a única apontada pelos participantes, embora enquadre duas estratégias de grande relevância: "contatar autoridades policiais" $(11,0 \%)$ e "ajudar a esclarecer os fatos" $(1,6 \%)$.

Já com relação às estratégias de apoio às vítimas, foram identificadas estratégias de ajuda direta, indireta e estratégias de evitamento. Neste sentido, pudemos perceber que as estratégias utilizadas pelos colegas para ajudar possuem fundamental importância seja no combate, como também na prevenção do cyberbullying.
Mais uma vezse acentua uma perspectiva de cuidado eresponsabilidade partilhada, onde todos possam e devam sentir-se autorizados a intervir, ajudando os que precisam de apoio.

\section{Estratégias dos Professores face ao Cyberbullying na Percepção dos Alunos}

Foram identificados três tipos de intervenções: primária, secundária e terciária e ambos os tipos apontam para focos diferenciados, o que tendencialmente poderá definir o tipo de uma ou mais estratégias utilizadas pelos professores. Salientam-se, como mais frequentes, as intervenções de prevenção primária, que ocorrem antes mesmo dos fenômenos de cyberbullying eclodirem. 
No âmbito das intervenções primárias, "observar o comportamento dos alunos" (16,1\%) e "dialogar e interagir com os alunos" (14,4\%), apresentam-se como estratégias focadas nos alunos. Já "alertar sobre os perigos das tecnologias" (26,7\%) e "realizar ações sobre o cyberbullying" $(18,6 \%)$ são consideradas como ações que podem ser realizadas pelos professores, com foco no problema e na sua prevenção. Trata-se não só de estar atento para intervir sobre os primeiros sinais, mas, sobretudo, de educar para uma relação saudável e eticamente orientada e de fortalecer os alunos para encontrarem em si os recursos para lidarem com os problemas mais autonomamente.

As intervenções secundárias focadas nos alunos mais significativas, apontadas pelos participantes, foram "prestar apoio às vítimas" $(13,5 \%)$ e "desincentivar o comportamento" (5,9\%). Já "buscar compreender o fato" $(5,0 \%)$, "informar sobre medidas a serem tomadas" $\mathrm{e}$ "incentivar a denúncia" (2,5\%), surgem como intervenções secundárias focadas no problema.

"Contatar pais ou encarregados de educação" (11,0\%) e "contatar apoio profissional" (3,3\%), foram apontadas como intervenções terciárias a serem realizadas pelos professores com foco nos alunos, e "envolver a comuni-

Tabela 3

Estratégias dos Pais face ao Cyberbullying na Percepção dos Alunos

\begin{tabular}{|c|c|c|c|c|}
\hline Categorias & & Indicadores & $f$ & $(\%)$ \\
\hline \multirow[t]{5}{*}{ Intervenções Primárias } & \multirow[t]{3}{*}{ Foco nos filhos } & Dialogar e interagir & 19 & 16,1 \\
\hline & & Fazer-se presente na vida dos filhos & 25 & 21,1 \\
\hline & & Educar para uma postura ética & 09 & 7,6 \\
\hline & \multirow[t]{2}{*}{ Foco no problema } & Controlar uso das tecnologias e redes sociais. & 24 & 20,3 \\
\hline & & $\begin{array}{l}\text { Alertar sobre os perigos das tecnologias e redes } \\
\text { sociais }\end{array}$ & 35 & 29,6 \\
\hline \multirow{6}{*}{$\begin{array}{l}\text { Intervenções Secundárias } \\
\text { Foco no problema }\end{array}$} & \multirow[t]{2}{*}{ Foco nos filhos } & Prestar apoio & 19 & 16,1 \\
\hline & & Desincentivar comportamento & 02 & 1,6 \\
\hline & \multirow[t]{4}{*}{ Foco no problema } & Incentivar e apoiar a vítima às medidas necessárias & 05 & 4,2 \\
\hline & & Dialogar com os agressores & 02 & 1,6 \\
\hline & & Buscar ajuda profissional & 03 & 2,5 \\
\hline & & Buscar compreender o fato & 02 & 1,6 \\
\hline \multirow[t]{3}{*}{$\begin{array}{l}\text { Intervenções Terciárias } \\
\text { Foco no problema }\end{array}$} & \multirow[t]{3}{*}{ Foco nos filhos } & $\begin{array}{l}\text { Contatar pais ou encarregados de educação dos } \\
\text { envolvidos. }\end{array}$ & 01 & 0,8 \\
\hline & & Contatar comunidade educativa & 04 & 3,3 \\
\hline & & Contatar autoridade policial & 05 & 4,2 \\
\hline Atitudes Negativas & & $\begin{array}{l}\text { Intervenção limitada } \\
\text { ou inexistente }\end{array}$ & 01 & 0,8 \\
\hline
\end{tabular}

Nota. O $f$ corresponde ao número de participantes que referiu cada uma das estratégias. A \% é calculada tendo por referência o total dos participantes, ou seja, 118 . dade educativa" $(1,6 \%)$ como uma intervenção com foco no problema.

Apesar das diversas estratégias indicadas, a serem tomadas pelos professores para ajudar em situações de cyberbullying, os participantes apontam para uma "intervenção limitada ou até mesmo inexistente" $(2,5 \%)$, o que pode ser considerado um dado importante tendo em vista a compreensão das dificuldades encontradas nas intervenções dos professores face ao fenômeno. Mais uma vez se acentua a necessidade de alertar a comunidade educativa para uma intervenção sistêmica e conjugada.

\section{Estratégias dos Pais face ao Cyberbullying}

na Percepção dos Alunos

Assim como os colegas e os professores, os pais também apresentam-se como agentes de significativa relevância no evitamento e combate do cyberbullying. Os alunos apontaram para três tipos de intervenções a serem realizadas pelos pais no enfrentamento do cyberbullying, sendo elas, intervenções primárias, secundárias e terciárias.

Foi possível verificar que as estratégias podem ser com focos distintos, embora com o mesmo objetivo: diminuir os impactos do cyberbullying, seja na vida das vítimas, das testemunhas, como também na vida dos agressores (Tabela 3 ). 
Souza, S. B., Veiga Simão, A. M. \& Caetano, A. P. (2014). Cyberbullying: Percepções acerca do Fenômeno e das Estratégias de Enfrentamento.

Como podemos constatar, tal fato nos sugere que "pais presentes, que interagem e se dedicam afetivamente aos filhos têm condições de identificar que tipo de relações eles vêm estabelecendo em seu cotidiano" (Vieira, Mendes, \& Guimarães, 2009, p. 499).

Mais uma vez se privilegia uma prevenção primária, focada no papel educativo dos pais, pelo alertar para os potenciais problemas e pelo controle do uso das tecnologias, mas também, e com mais destaque, ainda, pela qualidade de relação com os filhos. Como formas de prevenção secundária sobressaem estratégias focadas no apoio aos filhos. $\mathrm{Na}$ intervenção terciária, e com uma presença mais residual, referem o recurso a terceiros, privilegia-se o apoio das autoridades policiais e da comunidade educativa. Isso significa dizer que, conforme proposto por Pinto e Branco (2011), as famílias podem atuar no empoderamento da criança vítima de cyberbullying, fortalecendo-a a procurar ajuda quando se sentir agredida e, ainda, a lidar de forma defensiva e assertiva diante de situações indesejáveis.

\section{Considerações Finais}

O cyberbullying apresenta-se como um fenômeno atual, trazendo consigo repercussões incalculáveis na vida dos envolvidos, sobretudo nas vítimas. O impacto causado na vida das crianças e jovens, no que se refere ao curso normal da vida escolar, pode ser devastador. Conforme salientam Pinto e Branco (2011) sem dúvida, o bullying e o cyberbullying são expressões de preconceito e intolerância a tudo e a todos que sejam diferentes de um padrão idealizado por nossa sociedade de consumo. Como se já não bastassem os infortúnios da difamação a seu respeito, a vítima também encontrará em seu caminho alguns desafios peculiares das novas tecnologias em que o "mundo virtual" permite ao agressor sentir-se menos inibido e responsável por suas ações.

Apesar das investigações que objetivam compreender os fatores envolvidos no cyberbullying, os estudos existentes a respeito da problemática apontam que ainda há muito a ser compreendido em sua complexidade e extensão. Logo, compreender o fenômeno a partir da percepção dos alunos apresentou-se como de extrema importância para uma desmistificação daquilo que de fato acontece entre os estudantes e nas suas formas de relacionamento, seja em contexto real, ou até mesmo virtual, como no caso do cyberbullying.

De acordo com os objetivos propostos para o presente estudo, foi possível identificar a dimensão do fenômeno na vida dos estudantes, perceber qual a percepção dos alunos sobre o cyberbullying e sobre os modos de enfrentá-lo, como também, identificar os tipos de pedidos de ajuda no enfrentamento do problema, seja dos envolvidos diretamente com o fenômeno (vítimas, agressores e testemunhas), como também a forma como os pais e professores podem ajudar no enfrentamento do problema. Colegas, pais e escolas podem desempenhar um papel fundamental no sentido de não incentivar tal comportamento (Price \& Dalgleish, 2010).

A partir da análise realizada, verificou-se que 18,6(\%) dos inquiridos já foram em algum momento de sua vida "vítimas" de cyberbullying, 59,3(\%) "testemunharam" episódios de cyberbullying e 39,8(\%) "nunca estiveram envolvidos". Tais informações apontam que, em alguns casos, os participantes referiram ter vivenciado o fenômeno de forma mista, sendo em alguns casos como vítimas e em outros como testemunhas. Relativamente aos meios utilizados, o "computador" apresentou-se como o meio mais utilizado pelos participantes, seja através do messenger, Hi5 ou facebook, o que de certo modo se diferencia de outros estudos que apontam também para o uso de telefones celulares e o messenger como os principais meios utilizados pelos estudantes portugueses (Amado et al., 2009b; Castro, 2008).

Tendo como base o estudo realizado por Price e Dalgleish (2010) sobre as estratégias utilizadas para resolver o cyberbullying, buscamos verificar as estratégias offline e online realizadas pelas vítimas. Neste sentido, verificou-se que "fazer frente ao fato", "contactar as autoridades policiais", "procurar ajuda de alguém de confiança" e "pedir ajuda aos amigos", são as estratégias offline mais utilizadas pelas vítimas, na perspectiva dos participantes. Já "restringir e encerrar contatos" (e-mail e número de telefone celular), "excluir os agressores das redes sociais" e "contatar os gestores do site ou rede social" foram indicadas com maior frequência, pelos alunos, como estratégias online para o combate e prevenção do cyberbullying. Assim, Price e Dalgleish (2010) salientam o benefício fornecido pelo cyberespaço, no que diz respeito ao amplo conjunto de ferramentas disponibilizadas para a vítima, seja em momentos offline, online, ou até mesmo que podem ser utilizadas em ambos os momentos. Ferramentas que poderão e deverão ser integradas numa intervenção assente numa visão sistêmica, onde múltiplos agentes poderão confluir. Trata-se de promover o desenvolvimento de comunidades educativas, onde todos se sintam parte do problema, autorizados para intervir com responsabilidade e articuladamente na análise e resolução das situações. Trata-se de desenvolver uma sociedade, uma comunidade e uma escola inclusiva, eticamente justa e cuidadora.

O cyberbullying coloca os alunos em uma ilha virtual, sem supervisão e com poucas regras, o que permite que o bullying evolua, tornando-se perigoso, alcançando, até, níveis potencialmente fatais (Shariff, 2011). Desta forma, Amado et al. (2009b) salientam a importância e urgência de investigações que viabilizem possíveis compreensões do problema e, sobretudo, apontam intervenções possíveis, capazes de viabilizar uma ação educativa-preventiva que possibilite intervir de forma eficaz, criando assim um espaço propiciador do bem estar, da aprendizagem e do convívio social saudável a partir das tecnologias.

O cyberbulling pode ser visto como sintoma de uma violência social que apela ao nosso olhar e à nossa denúncia, para ser transformado em outra coisa. É preciso 
uma visão esclarecida, complexa, e, sobretudo, sistêmica. Uma visão que não seja cega à radicalidade das estruturas, do antagonismo, dos conflitos, mas que perceba neles e que através deles poderá concorrer para a mudança (Morin, 1986; Petraglia, 2001). Mudança que se opera quando percebemos que os agressores e as vítimas são partes intermutáveis do mesmo, a um tempo sujeitos e objetos, ambos presos na mesma armadilha e da qual só poderão ser resgatados quando se abrir o círculo. Um círculo onde os rótulos, os preconceitos, os julgamentos são escrutinados para poderem ser transmutados. Um círculo onde os próprios percebem que também há neles parte da responsabilidade de se libertarem. Um círculo onde se percebe que a dor não é só naqueles que se refugiam no silêncio. Um círculo onde é possível em conjunto procurar as respostas. Abrindo-se a uma dinâmica ela própria imprevisível, da qual não há garantias de quais serão os resultados. Uma incerteza também ética, que decorre da ecologia da ação, das contradições éticas e que esconde uma aparência unívoca de bem e do mal. Uma incerteza que é preciso enfrentar com um pensamento complexo e com um conhecimento "capaz de conceber as condições da ação e a ação ela própria, de contextualizar antes e durante a ação" (Morin, 2004, p. 61).

Esperamos desta forma, ter contribuído para esse conhecimento e essa intervenção, partindo das experiências no terreno e ouvindo os alunos que direta ou indiretamente estão envolvidos ou testemunham este tipo de situações.

\section{Referências}

Amado, J. S. (2000). A técnica da análise de conteúdo. Revista Referência, 5, 53-63.

Amado, J., Matos, A., \& Pessoa, T. (2009a). Cyberbullying: Um novo campo de investigação e de formação. In Actas do $X$ Congresso Internacional Galego-Português de Psicopedagogia (pp. 262-273). Braga, Portugal: Universidade do Minho. Recuperado em http://www.educacion.udc.es/grupos/gipdae/ documentos/congreso/Xcongreso/pdfs/t1/t1c11.pdf

Amado, J., Matos, A., \& Pessoa, T. (2009b). Cyberbullying: The situation in Portugal - Country report. In Relatório de investigação no âmbito do projeto cybertrayning: Tacking action against cyberbullying. Coimbra, Portugal: Universidade de Coimbra. Retrieved from http://www.cybertraining-project. org/page.php?lang $=$ Pt\&page $=8$

Bardin, L. (2009). Análise de conteúdo (5. ed.). Lisboa, Portugal: Edição 70.

Campbell, M. (2005). Cyberbullying: An old problem in a new guise? Australian Journal of Guidance and Counseling, 1(15), 68-76.

Cardoso, G., Espanha, R., \& Lapa, T. (2007). E-Generation: Os usos de media pelas crianças e jovens em Portugal (Relatório Final). Lisboa, Portugal: Centro de Investigação e Estudos em Sociologia, Instituto Superior de Ciências do Trabalho e da Empresa. Recuperado em http://cies.iscte.pt/destaques/ documents/E-Generation.pdf

Castaño, E. F., \& Barco, B. L. (2010). Estrategias de afrontamiento del estrés y estilos de conducta interpersonal. International Journal of Psychology and Psychological Therapy, 10(2), 245-257. Recuperado em http://www.ijpsy.com/volumen10/ num2/260/estrategias-de-afrontamiento-del-estres-ES.pdf
Castro, T. (2008). Quando as teclas falam, as palavras calamEstudo sobre a utilização do telemóvel e do messenger por crianças do $5^{\circ}$ e $6^{\circ}$ ano do Distrito de Braga (Dissertação de mestrado, Universidade do Minho, Braga, Portugal).

Castilho, A. E. (2010). Estudio descriptivo de las estrategias de afrontamiento del bullying, en professorado mexicano. Electronic Journal of Research in Educational Phychology, 8(1), 353-372. Recuperado em http://redalyc.uaemex.mx/src/ inicio/ArtPdfRed.jsp?iCve $=293121995017$

Francisco, M. V., \& Libório, R. M. C. (2009). Um estudo sobre bullying entre escolares do ensino fundamental. Psicologia: Reflexão e Crítica, 22(2), 200-207.

Freire, I., Veiga Simão, A. M., \& Ferreira, A. (2006). O estudo da violência entre pares no $3^{\circ}$ ciclo do ensino básico - Um questionário aferido para a população portuguesa. Revista Portuguesa de Educação, 19(2), 157-183.

Grupo Marktest. (2008). Quatro milhões de utilizadores de internet: Bareme internet. Recuperado em http://www.marktest. com/wap/a/n/id 1180.aspx

Morin, E. (1986). O método III - O conhecimento do conhecimento. Lisboa, Portugal: Publicações Europa América.

Morin, E. (2004). La méthode 6. Éthique. Paris: Seuil.

Olweus, D. (1978). Aggression in the schools: Bullies and whipping boys. Washington, DC: Hemisphere.

Organização Mundial de Saúde. (2002). Relatório mundial sobre violência e saúde. Genebra, Suíça: Autor. Recuperado em http://www.opas.org.br/cedoc/hpp/ml03/0329.pdf

Petraglia, I. (2001). Complexidade, holística e educação. Petrópolis, RJ: Vozes

Pinto, R. G., \& Branco, A. U. (2011). O bullying na perspectiva sociocultural construtivista. Revista Teoria e Prática da Educação, 14(3), 87-95.

Price, M., \& Dalgleish, J. (2010). Cyberbullying: Experiences, impacts and coping strategies as described by Australian young people. Youth Studies Australia, 29(2), 51-59. Retrieved from http://kidshelp.com.au/upload/22882.pdf

Shariff, S. (2011). Cyberbullying: Questões e soluções para a escola, a sala de aula e a família. Porto Alegre, RS: Artmed.

Silva, J. L., \& Mascarenhas, S. A. N. (2010). Gestão do bullying e cyberbullying na universidade - Desafios para a orientação educativa e convivência social e ética no ensino superior Estudo com estudantes da UFAM/Brasil. Revista AMAzônica, 5(2), 46-55.

Slonje, R., \& Smith, P. K. (2008). Cyberbullying: Another main type of bullying? Scandinavian Journal of Psychology, 49, 147-154.

Souza, S. B. (2011). Cyberbullying: Estudo exploratório sobre as perspectivas acerca do fenómeno e das estratégias de enfrentamento com jovens universitários portugueses (Dissertação de mestrado, Faculdade de Psicologia, Universidade de Lisboa, Portugal).

Vieira, T. M., Mendes, F. D. C., \& Guimarães, L. C. (2009). De Columbine à Virgínia Tech: Reflexões com base empírica sobre um fenômeno em expansão. Psicologia: Reflexão $e$ Crítica, 22(3), 493-501. 